\title{
O PAPEL DA IIRSA NA PRODUÇÃO ATUAL DO CERRADO: IMPULSÃO DA EXPORTAÇÃO DE SOJA PARA O MERCADO CHINÊS E OS CONFLITOS TERRITORIAIS
}

\author{
Pedro Dias Mangolini NEVES ${ }^{1}$ \\ Marcelo Rodrigues MENDONÇA ${ }^{2}$
}

\section{Resumo}

Este trabalho tem por objetivo problematizar os processos de integração regional em curso atualmente na América Latina. Nisto leva-se em consideração, especificamente, a Iniciativa para Integração da Infraestrutura Regional Sul-Americana (IIRSA) e sua relação com a impulsão da exportação de soja para o mercado chinês através da construção da Ferrovia Transoceânica (conectando o Oceano Atlântico ao Pacífico por meio de uma ferrovia) e consequentemente os conflitos territoriais que serão causadas por ela. Esta iniciativa de integração se estabelece na lógica de que há "vazios demográficos" no continente que estão bloqueando o desenvolvimento (visto como desenvolvimento econômico). Assim, tem sido dominante uma visão onde a natureza e Comunidades Tradicionais têm seus territórios e suas vidas concebidas como simples obstáculo a ser superado. Deste modo, as expropriações de muitas populações de suas terras, bem como a ocorrência de inúmeros conflitos territoriais, têm sido recorrentes na execução dos empreendimentos de integração de infraestrutura regional ora em curso.

Palavras-chave: Integração regional. América Sul. Cerrado. Conflitos territoriais.

\section{Abstract}

\section{The role of IIRSA in the current production of cerrado: soy export push for chinese market and territorial conflicts}

This work aims to discuss the regional integration processes currently under way in Latin America. It takes into account, specifically, the Initiative for Integration of Regional Infrastructure in South America (IIRSA) and its relationship to push soybean export to the Chinese market through the construction of transoceanic railroad (connecting the Atlantic Ocean to the Pacific by a middle rail) and consequently the regional conflicts are caused by it. This integration initiative is established on the logic that there are "demographic gaps" on the continent that are blocking the development (seen as economic development). So dominant has been a vision where nature and traditional communities have their territories and their lives designed as a simple obstacle to overcome. Thus, the expropriations of many peoples from their lands, as well as the occurrence of numerous territorial conflicts have been recurrent in the implementation of regional infrastructure integration projects now underway.

Key words: Regional integration. South America. Cerrado. Territorial conflicts.

\footnotetext{
1 Doutorando em Geografia pela Universidade Federal de Goiás - UFG/IESA. Membro do TRAPPU - Grupo de Pesquisa Trabalho, Território e Políticas Públicas e do LABOTER - Laboratório de Estudos e Pesquisas das Dinâmicas Territoriais. E-mail: pmangolini@hotmail.com

2 Doutor em Geografia pela Universidade Estadual Paulista - UNESP campus de Presidente Prudente e Docente do Programa de Pós-Graduação em Geografia da Universidade Federal de Goiás - UFG/IESA. Coordenador do TRAPPU - Grupo de Pesquisa Trabalho, Território e Políticas Públicas e membro do LABOTER - Laboratório de Estudos e Pesquisas das Dinâmicas Territoriais. E-mail: ufgmendonca@gmail.com
}

GeOgRAfIA, Rio Claro, v. 43, n. 2, p. 223-235, mai./ago. 2018. 


\section{INTRODUÇÃO}

A partir do início do século XXI, uma nova fase da inserção da América Latina na economia mundial começa a se configurar e um novo padrão de desenvolvimento regional passa a estar em disputa na região. Esse processo ocorre em um contexto de relativa crise do neoliberalismo no continente, de ascensão de governos que se apresentam fora dessa agenda política e da centralidade econômica que a Ásia passa a exercer no cenário mundial (MARTINS, 2011).

É neste contexto que a partir da década de 2000 são propostos na América do Sul a execução de grandes empreendimentos visando à integração da infraestrutura regional. Tais empreendimentos encontram-se articulados em torno da Iniciativa para Integração da Infraestrutura Regional Sul-Americana - IIRSA, que se trata de um megaprojeto centrado essencialmente nos setores de transporte, energia e telecomunicações e pretende criar grandes canais multimodais, com mais de 300 (trezentas) obras que incluem a construção de rodovias, pontes, hidroelétricas, gasodutos e outras obras.

Desse modo, por meio da IIRSA, a América do Sul se transformaria em peça chave no mercado internacional, por conta da exploração dos recursos naturais do território, tais como fontes de água, de minérios, petróleo e gás, via empresas transnacionais brasileiras, exportação de commodities, como a soja, e usando corredores industriais do subcontinente, passando por áreas de biodiversidade mundialmente importantes e também por reservas indígenas e de Comunidades Tradicionais.

Se baseando apenas na produção de soja, o Brasil é o segundo maior exportador mundial, exportando soja em grão para principalmente países da União Européia e China. Segundo Coronel et al (2008), o Brasil é competitivo no que tange às exportações do complexo soja, contudo vários obstáculos ainda têm que ser superados para que aumente sua participação no mercado mundial de soja. Alguns são de ordem interna, como maior integração entre os elos da cadeia produtiva e custos de produção, outros, de ordem externa, como a redução de barreiras que os principais importadores impõem.

Para este estudo presumimos que a IIRSA se baseia principalmente na produção de circulação e transporte gerando uma interligação do Atlântico com o Pacífico, e consequentemente ligando o cerrado com a Ásia através da Amazônia.

Assim, esta pesquisa tem como objetivo compreender a IIRSA, avaliar a consequente impulsão da exportação de soja para a China, nosso maior consumidor de soja e, assim identificar os possíveis conflitos territoriais que serão gerados pela efetivação da IIRSA, como a expropriação de muitas populações de suas terras, não somente na construção das vias de transporte, mas também na expansão da soja no cerrado.

\section{METODOLOGIA}

A referida pesquisa se baseará na discussão sobre a relação comercial de commodities agrícolas do Brasil com a China, que se fundamenta principalmente na exportação de soja (produzida principalmente no Cerrado) para a China, a IIRSA e seu papel fundamental na expansão deste monocultivo no Brasil e, uma discussão acerca de qual desenvolvimento estamos falando, e para quem é este desenvolvimento que se busca através da IIRSA. 
Contrapondo a este desenvolvimento escolhido pelo Estado, temos diversos sujeitos sociais que vivem nestas regiões, tanto as que sofrerão efeitos socioespaciais pela construção destes eixos de integração, com suas rodovias e ferrovias, quanto às regiões onde o complexo da soja avançará, e deste modo foi verificado, através de dados do Boletim de Conflitos no Campo da Comissão Pastoral da Terra - CPT, o aumento destes conflitos.

Foi verificado também, através de dados da ANEC - Associação Nacional de Exportadores de Cereais qual a real importância do mercado chinês para a produção de soja brasileira e a importância de cada região na produção desta commoditiy.

\section{IIRSA}

Segundo Porto-Gonçalves e Quental (2012), entre os principais agentes financiadores das obras e projetos da IIRSA se destacam o Banco Interamericano de Desenvolvimento - BID, a Corporação Andina de Fomento - CAF, o Fundo Financeiro para Desenvolvimento da Bacia do Prata - FONPLATA e o Banco Nacional de Desenvolvimento Econômico e Social - BNDES, que financiaram a construção de estradas, hidrovias e ferrovias, redes de comunicação, portos, aeroportos e construção de barragens hidrelétricas e integração energética.

A IIRSA é composta por 10 (dez) Eixos de desenvolvimento com rodovias, hidrovias e ferrovias (Figura 1).

De um modo geral, o principal objetivo desses eixos é estabelecer corredores de desenvolvimento interligando a América do Sul do Atlântico ao Pacífico, a partir da construção de estradas, hidrovias e ferrovias, redes de comunicação, portos, aeroportos e construção de barragens hidrelétricas e integração energética (PORTO-GONÇALVES; QUENTAL, 2012).

A origem da IIRSA é baseada na década de 1990, quando foram formulados no Brasil os Eixos Nacionais de Integração e Desenvolvimento - ENID, com o objetivo da construção de um sistema integrado de logística capaz de promover a competitividade dos produtos brasileiros, da incorporação de novas áreas do país à dinâmica do comércio global e da consolidação da hegemonia política e econômica do Brasil na América do Sul (VERDUM, 2007).

Complementando, Verdum (2007) descreve que os Planos Plurianuais - PPA do Governo Federal foram estabelecidos a partir da noção de Eixos Nacionais de Integração e Desenvolvimento, em programas como: Brasil em Ação (1996-1999), Avança Brasil (2000-2003) e Brasil de Todos (2004-2007), que tiveram como destaque obras de infraestrutura para integração física do país, como a recuperação e construção de rodovias, a construção de hidrovias, instalação de gasodutos, entre outros. 


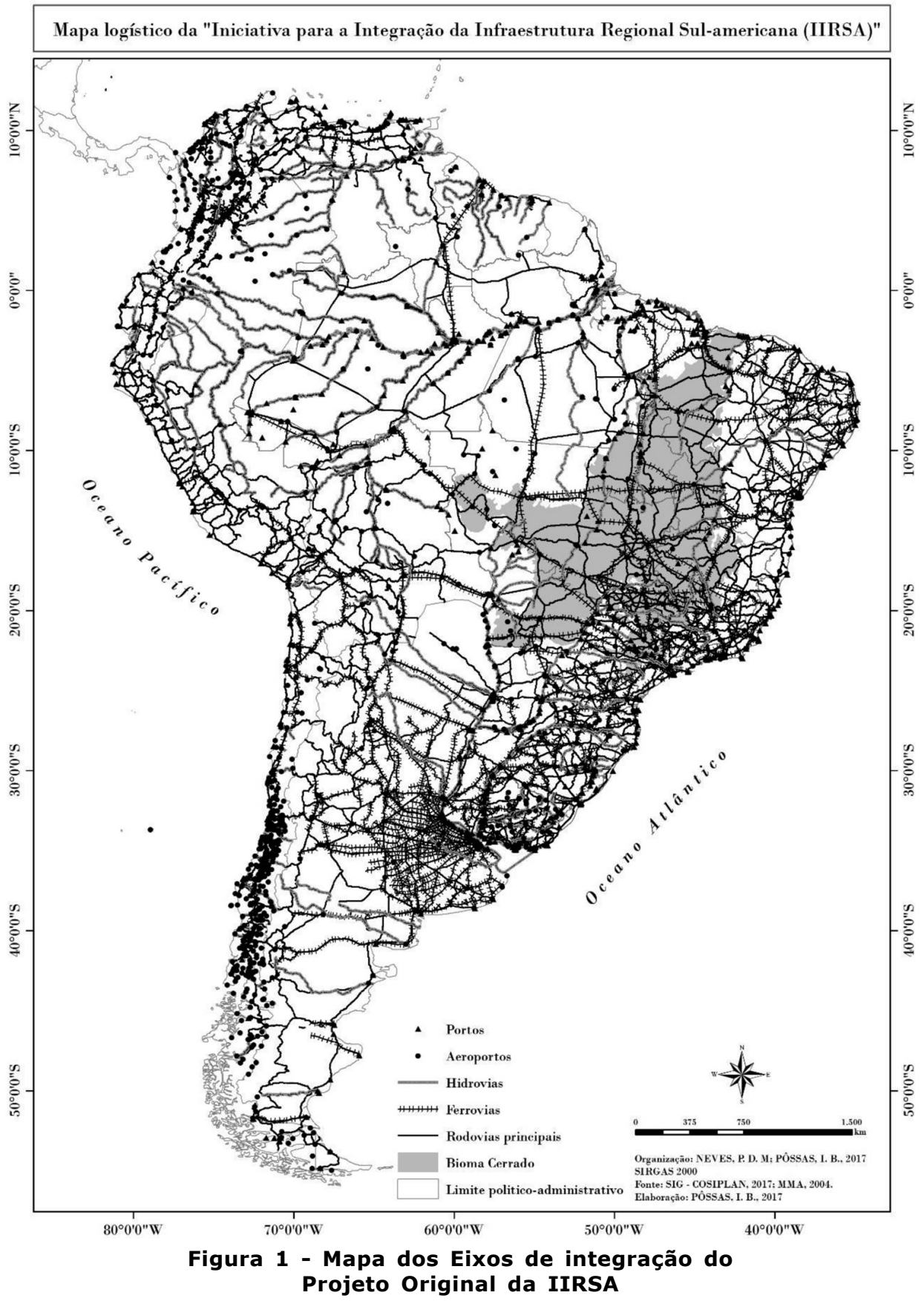

Fonte: COSIPLAN (2017) 


\section{FERROVIA TRANSOCEÂNICA}

A IIRSA avança a pleno vapor e a América Latina sofre processos concorrentes de integração subordinada. O Peru tem um Tratado de Livre Comércio - TLC com a China e esta ferrovia seria uma via de escoamento integrado para dois projetos concorrentes de integração pela via do Pacífico: um, com a China, que financia a infraestrutura; outro, na projeção da Integração do Pacífico através dos EUA, por sinal concorrente com a China e pressionando a Aliança do Pacífico (Chile, Peru, Colômbia e México) para isso. Ambos movimentos são de "recolonização" de nosso Continente, pela ênfase em transformar os territórios latino-americanos em vastas plantations e também em converter manufaturas importadas em produtos não taxados e com selo de nacionalização, que é o que o Paraguai faz há mais de 40 anos, começando com a relação Assunção-Taipei (VERDUM, 2007).

O protocolo é resultado de uma parceria estratégica firmada entre os dois países e os 35 (trinta e cinco) acordos assinados pela então presidente Dilma Rousseff e o primeiro-ministro da China, Li Keqiang. Um deles prevê o estudo de viabilidade de implantação da Ferrovia Transoceânica, que, pelo projeto, sai do Rio de Janeiro, passa por Minas Gerais, Goiás, Mato Grosso, Rondônia, Acre e termina no Peru (G1, 2015).

A China quer aumentar os negócios na América Latina, e facilitar o acesso à produção brasileira, principalmente de soja, sem depender do Canal do Panamá, que tem forte influência dos Estados Unidos. Mas para se tornar realidade, o projeto tem que enfrentar desafios de engenharia, ambientais e políticos.

Segundo matéria do The Economist (2015), especialistas afirmam que os investimentos na ferrovia podem ficar próximos a $R \$ 30$ bilhões e, os mais beneficiados seriam os produtores rurais do Oeste de Mato Grosso, que teriam um caminho mais curto para escoar a safra, principalmente de soja, reduzindo o transporte pelas rodovias. Em 2014, a China importou de Mato Grosso produtos no valor de US\$ 4,9 biIhões, sendo que US $\$ 4,6$ bilhões foram destinados à importação de soja, conforme dados do Ministério do Desenvolvimento, Indústria e Comércio Exterior - Mdic.

O interesse da China no desenvolvimento de infraestrutura da América Latina não é altruísta, mas sim reduzir os custos de transporte das suas importações, como de soja do estado de Mato Grosso. Estima-se que haja uma economia de U\$30,00 por tonelada de grãos exportada (THE ECONOMIST, 2015).

\section{COMMODITIES DO CERRADO E MERCADO CHINÊS}

Segundo Coelho (2001) o grande crescimento da produção de grãos (principalmente da soja) foi a força motriz no processo de transformação da agricultura brasileira e, portanto, da expansão e fortalecimento do agribusiness. Entre 1970 e 2000, a produção nacional de grãos passou de 29,2 milhões de toneladas para 82,8 milhões de toneladas, um crescimento de $184 \%$. Grande parte dessa expansão ocorreu nos cerrados.

De acordo com a figura 2, do gráfico de exportação de soja brasileira de 2008 a 2015, desenvolvido através dos dados da Associação Nacional de Exportadores de Cereais, pode-se notar a grande dependência da China pela produção de soja, sendo responsável por aproximadamente $75 \%$ das exportações da soja brasileira no ano de 2015. Numa visível crescente nos números de exportação, a China certamente au- 
mentará sua participação no número de exportações deste cereal a partir da efetivação da Ferrovia Transamazônica.

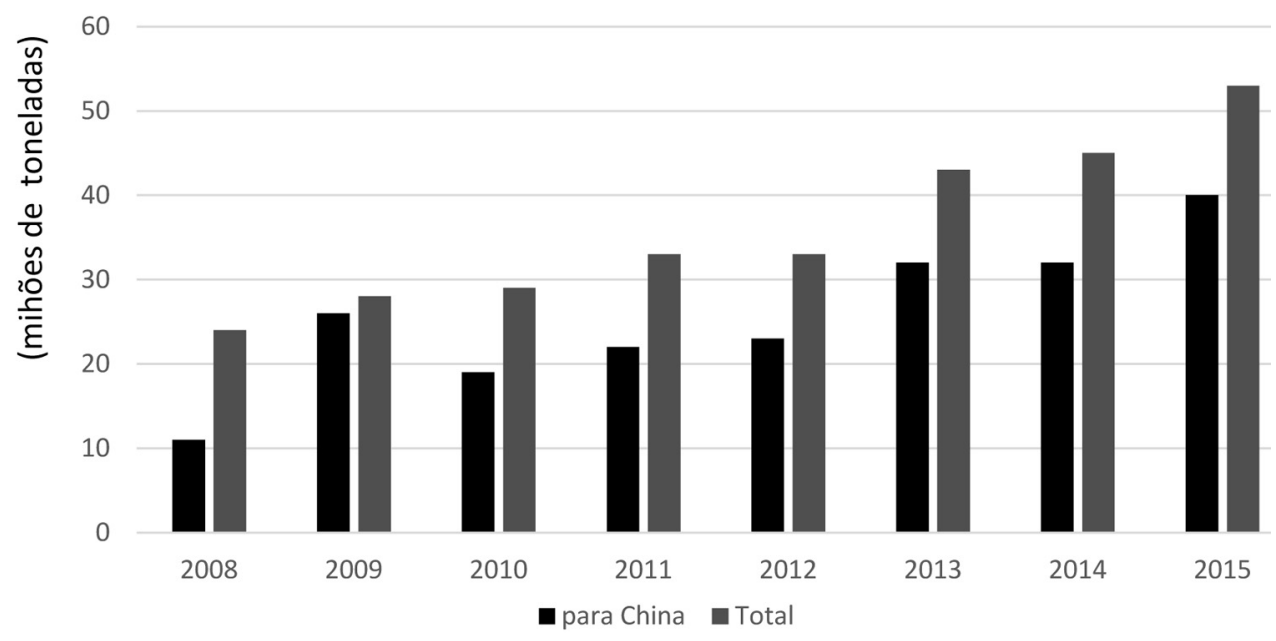

Figura 2 - Gráfico de exportação de Soja brasileira em grãos - 2008 a 2015

Fonte: ANEC, 2016

O escoamento desta produção é realizado principalmente através dos portos localizados nas regiões Sul e Sudeste, sendo os principais portos o de Santos-SP, Paranaguá-PR, São Francisco do Sul-SC e Rio Grande-RS, que juntos somam aproximadamente $75 \%$ das exportações de grãos de soja (ANEC, 2016).

$\mathrm{Na}$ Figura 3 podemos observar que os estados com maior produção de soja em grãos para exportação estão localizados respectivamente na região Centro Oeste e Sul, totalizando cerca de $80 \%$ das exportações, que são escoadas pelos portos já descritos.

E com o mapa de expansão da sojicultora no Brasil (Figura 4), levando em consideração os anos 2005, 2010 e 2015, podemos inferir que o cultivo da soja foi expandido no Cerrado, principalmente na região dos estados de Maranhão, Tocantins, Piauí e Bahia, região conhecida pelas iniciais destes estados, MATOPIBA, e que vem se configurando como a nova área de expansão agrícola.

Deste modo, pode-se inferir que com a IIRSA a produção da soja, sendo cerca de $70 \%$ exportada para a China e com esta nova rota seria através do Oceano Pacífico, fomentaria uma diminuição do fluxo de transportes nas vias para estes portos na região sul e sudeste, e com uma maior expectativa, se aumentaria ainda mais a produção desta commodity.

O IIRSA abriu um espaço de diálogo e cooperação multilateral e multissetorial para que essas nações pudessem impulsionar ações para o desenvolvimento da infraestrutura regional dentro de um quadro de competitividade crescente. Uma meIhora da infraestrutura física gera novas oportunidades, facilita o comércio regional, porém sempre num viés empreendedor e não de melhora das condições de acessibilidade aos serviços básicos a populações mais isoladas e pobres (Amigos da Terra; Rios Vivos, 2004). 


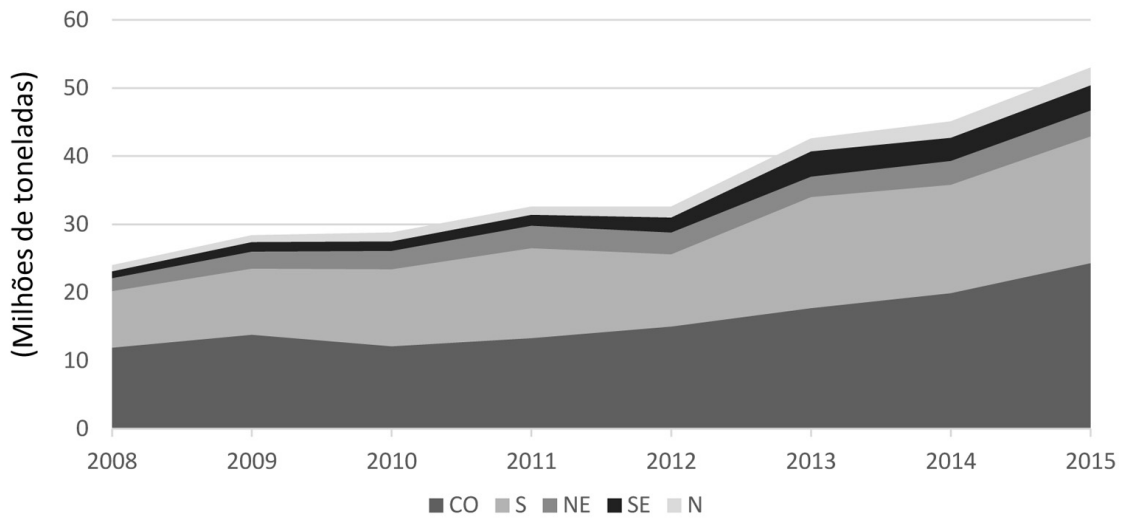

Figura 3 - Gráfico da evolução das exportações de soja em grãos por região - 2008 a 2015

Fonte: ANEC, 2016

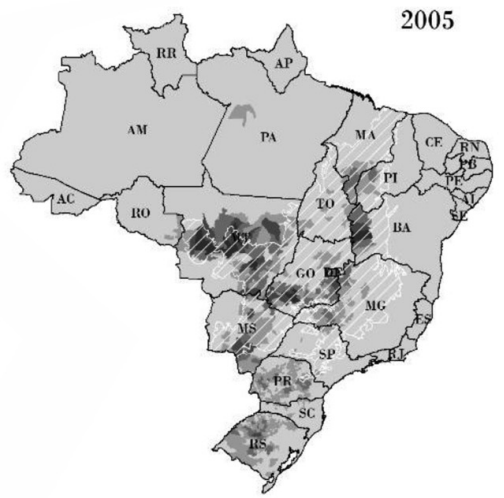

2015

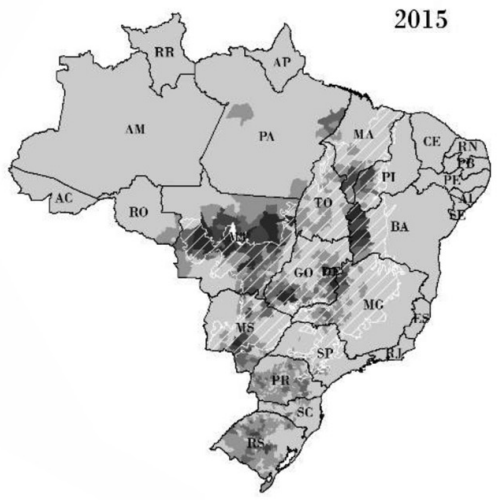

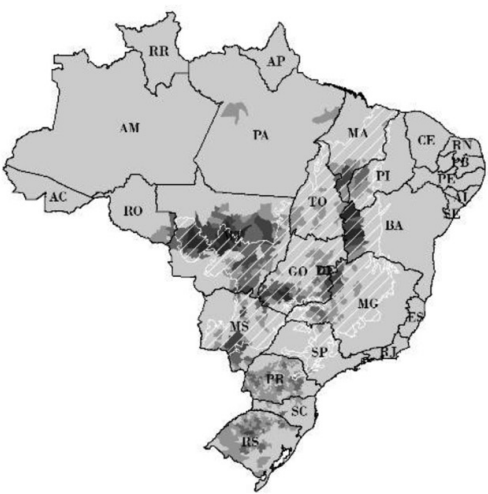

Área plantada (ha)
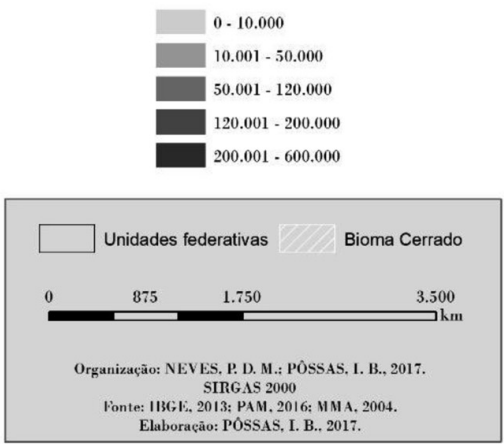

Figura 4 -: Mapa de expansão do cultivo da soja no Brasil (2005/2010/2015)

Fonte: IBGE (2016) 


\section{CONFLITOS TERRITORIAIS DA IIRSA}

A expansão da IIRSA tem gerado intenso debate na região Sul-Americana, haja vista os diferentes impactos produzidos. Os defensores da operação exaltam a intensificação dos processos de integração regional, dinamização econômica dos países da região mediante a redução dos custos operacionais, ampliação das vantagens competitivas e possibilidades de desencadeamento de desenvolvimento local. Já as organizações não governamentais, movimentos socioterritoriais, indígenas e povos originários denunciam que os megaprojetos desrespeitam as respectivas territorialidades, promovem a apropriação da etnobiodiversidade e a mercantilização das águas, terras, florestas e recursos minerais, violam territórios sagrados e aprofundam a expropriação mediante a prática da violência (OLIVEIRA et al, 2013).

Sobre isto, através do Mapa de distribuição das Unidades de Conservação, de Terras Indígenas e Territórios Quilombolas no Brasil (figura 5), podemos identificar principalmente Unidades de Conservação e Territórios Quilombolas que estão e serão afetados pela expansão do cultivo da soja. Observando a Figura 1 e a figura 5, é também verificável que, como Oliveira et al (2013) relatou, os eixos de integração da IIRSA afetarão tanto as comunidades tradicionais, como Terras Indígenas e Territórios Quilombolas, quanto a natureza, como as Unidades de Conservação.

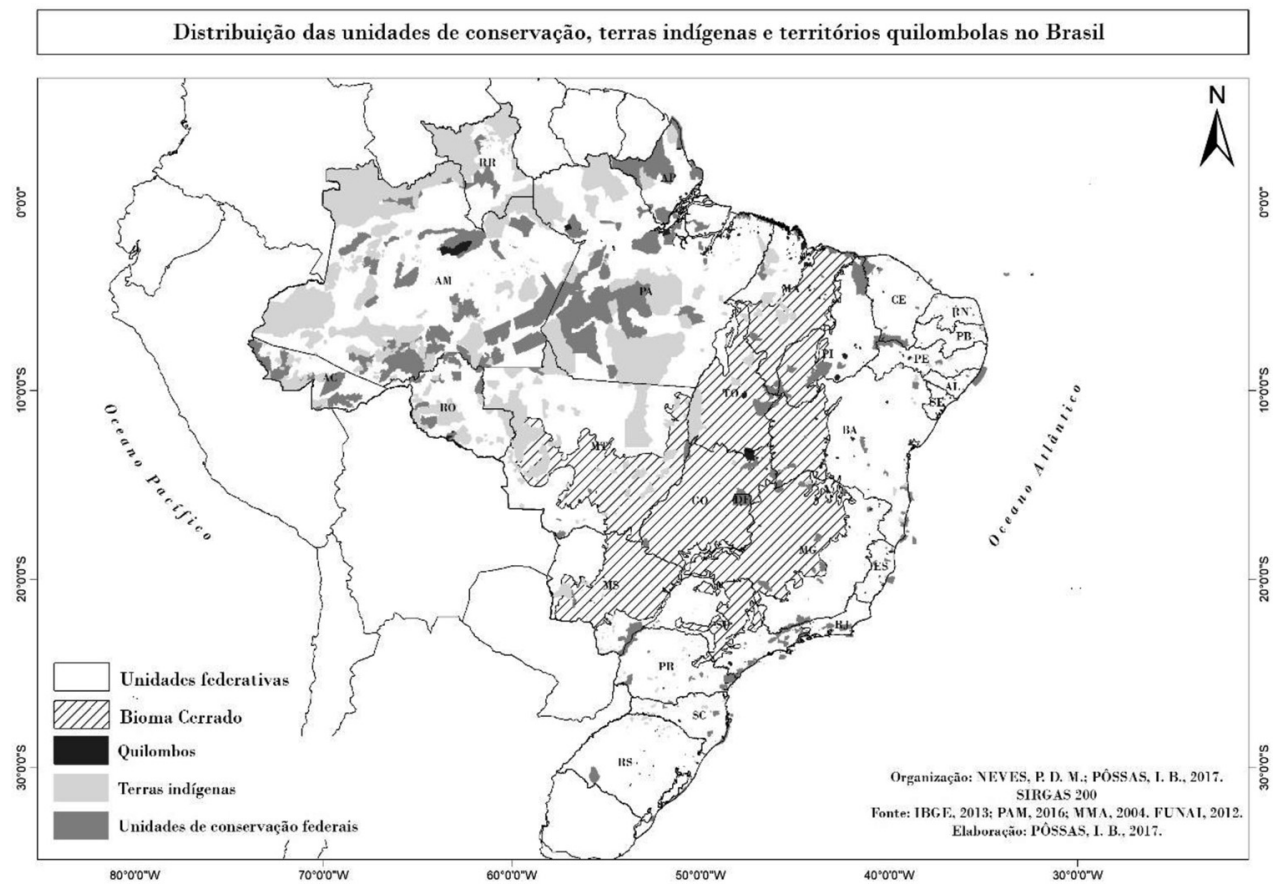

Figura 5 - Mapa de distribuição de Unidades de Conservação, terras indígenas, e territórios quilombolas no Brasil

Fonte: MMA (2004); FUNAI (2012); INCRA (2013) 
É nesse sentido que as formas geográficas aparecem como um poderoso instrumento do capital nas relações internacionais, ou segundo Santos (1979), como um novo "Cavalo de Tróia", na medida que permitem intervenções funcionais à expansão do modo de produção Capitalista, ao serem anunciadas como resultado dos interesses comuns dos países. Esses grandiosos objetos técnicos, custeados pela sociedade, através por exemplo do BNDS, revestem-se das promessas de desenvolvimento (econômico), geração de emprego e competitividade, novo mote dos governos dos países pobres. Na prática, implantam a desordem na escala local, e alienação em escala nacional, na medida que servem a reduzidas frações do Capital nacional e estrangeiro, pondo em risco a soberania nacional.

Toda a infraestrutura visa reduzir custos de produção dos principais produtos do continente, tentando cobrir eficientemente as áreas que são os principais recursos naturais, e conectando os principais pontos deste volume de produção, pensando principalmente na exportação continental, destarte a IIRSA surge como um projeto de integração regional Sul-Americana que busca a integração com países que não fazem parte da América do Sul, agindo assim de forma a desintegrar a América do Sul.

Bartesaghi et al (2006) pela Rede Amigos de La Tierra do Uruguai sintetizaram os impactos do IIRSA para os povos Sul-americanos. A fim de ser capaz de projetar ao longo do tempo, avaliar e sintetizar os impactos potenciais que a implemente ação da iniciativa poderia levar a uma matriz de impacto ambiental, em que três domínios foram considerados: físico-biológico, socioeconômico e político.

No domínio físico-biológico são entendidos como a própria natureza, como a fauna e flora, água, as fontes de energia fósseis e os minerais. Já o domínio socioeconômico foi divido em dois grupos, os efeitos nas áreas urbanas e rurais, pois os efeitos espaciais são diferentes nestas duas áreas, e mesmo dentro destes dois grupos há especificidades, como por exemplo, o rural, que possui distintos sujeitos sociais que sofrerão impactos diferenciados, como os latifundiários e os camponeses. E por fim, o domínio político que apresenta a discussão sobre o impacto da IIRSA para a soberania dos estados nacionais da América do Sul.

Assim, os efeitos territoriais decorrentes da construção da ferrovia transoceânica não serão somente impactos relacionados a construção desta via de transporte, mas também de conflitos causados pela expansão da produção de soja no cerrado, com expropriação de camponeses, diminuição da produção de alimentos, contaminação da natureza pela utilização massiva de agrotóxicos e soja transgênica, dentre outros.

No entanto, a IIRSA tem uma particularidade: é um tipo de integração nascido no Sul, gerido em grande parte, pelas elites do $\mathrm{Sul}^{3}$, mas os benefícios são destinados para os melhores setores do mercado de inserções internacionais. A ênfase na infraestrutura parece estar ligada à necessidade de mercados globais para alcançar um fluxo sustentado e aumento constante das exportações de matérias-primas e recursos naturais. E para fazê-lo "competitivos", ou seja, com redução de custos. É evidente que este tipo de desenvolvimento vai gerar mais pobreza e desigualdades, aumento de concentração da riqueza em escala local e global e, terá profundos impactos territoriais. Entre outras consequências negativas, a dívida externa dos países da região vai continuar a crescer e a superexploração dos recursos em alguns países que têm petróleo ou gás como seus principais ativos acabam por se esgotar sem obter qualquer vantagem (ZIBECHI, 2006).

\footnotetext{
3 Apesar de viabilizar metas de acordos anteriores como da ALCA, deste modo, firmados a partir do Norte. Findando numa ação gerida pelo Sul, em consonância com o Norte, numa inserção regional às metas da globalização econômica e controle total do espaço mundial da elite do capital mundial.
} 
Em pesquisa realizada pelo LEMTO (Laboratório de Estudos de Movimentos Sociais e Territorialidades da Universidade Federal Fluminense), foram identificados ao longo dos Eixos da IIRSA múltiplas ações de grupos sociais que defendem seus espaços que vêm sendo ameaçados pela expansão dessas obras e dos interesses que Ihes acompanham. Neste levantamento foram identificados mais de 555 diferentes povos indígenas, 222 comunidades camponesas, 115 comunidades de pescadores, 199 comunidades quilombolas, 45 comunidades de faxinalenses, 61 organizações sociais, 36 entidades ambientalistas, além de mais de 70 grupos diversificados, enfim, são cerca de 900 territorialidades identificadas que promovem algum tipo de mobilização contrária a efetivação da IIRSA, indicando assim potenciais conflitos territoriais da IIRSA (PORTO-GONÇALVES; QUENTAL, 2012).

Buscando compreender melhor tais conflitos foi realizado um Mapa da expansão dos conflitos no Campo no Brasil (Figura 6) através de dados da Comissão Pastoral da Terra - CPT.
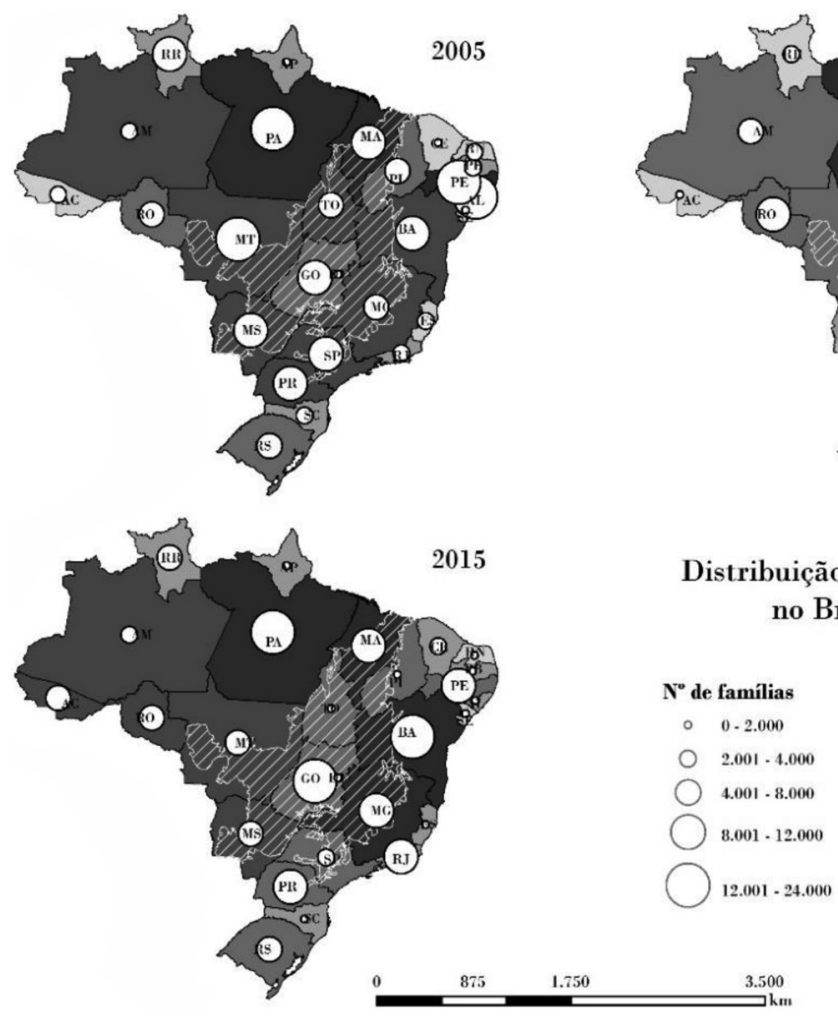

2010
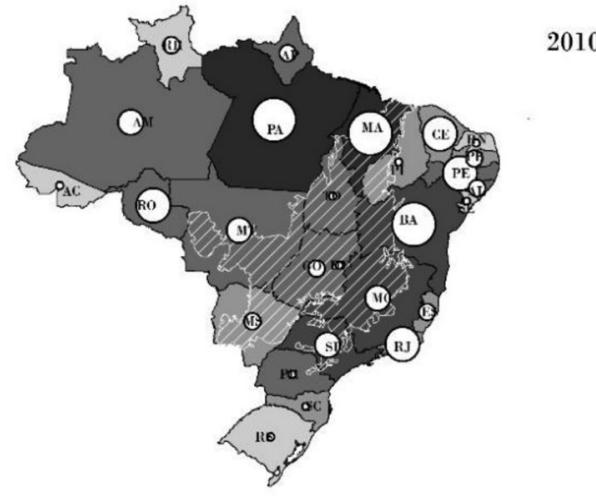

\section{Figura 6 - Mapa de expansão dos Conflitos no Campo no Brasil (2005/2010/2015)}

Fonte: CPT (2006; 2011; 2016)

De acordo com os dados da CPT, os conflitos no campo foram se expandido para a região do Cerrado, majoritariamente no estado do Pará, estado com grande 
quantidade de conflitos no campo, seguido do aumento dos estados de Maranhão, Bahia e Minas Gerais.

Acreditamos que seja necessário expor que os efeitos do IIRSA em um ponto do continente fazem parte de um mesmo plano de dominação em outro ponto distante. Entendemos que resistir ao plano IIRSA é trabalhar em prol de uma sociedade mais solidária às Comunidades Tradicionais e dedicadas a uma atividade que possa coexistir em equilíbrio com a natureza. Unificando, desta forma, nossas lutas contra algo que é comum a todas e a todos, este sistema econômico insustentável que só faz usurpar a natureza e o trabalho humano.

\section{CONSIDERAÇÕES FINAIS}

O projeto IIRSA tem uma estrutura claramente neoliberal e pensada de forma a eliminar as debilidades que dificultam a execução deste projeto, sua concretização facilitará o acesso aos recursos naturais estratégicos da região, aprofundando a exploração nos países sul-americanos.

O projeto de integração física sul-americana busca inserir os países na divisão internacional do trabalho em conformidade com o frágil pressuposto de que a atração de empresas está necessariamente ligada ao desenvolvimento, na ideia de crescimento econômico. Porém, ao invés de elevar os países da região a uma posição superior na divisão internacional do trabalho, os dados mostram que está em curso um processo de especialização regressiva ou reprimarização das economias nacionais.

Este processo deve ter consequências trágicas para o meio ambiente e para as populações locais, como o recente processo migratório de indústrias pesadas, que saem de seus países de origem com destino à América do Sul, em busca de maiores vantagens competitivas e fontes abundantes de matérias primas é apenas um exemplo dos problemas que virão pela frente. Após serem recusadas em seus países de origem em função de suas atividades altamente poluidoras, estas empresas encontram aqui condições ideais para desenvolver suas atividades.

Assim, o Programa IIRSA visa dar corpo físico às articulações comerciais anteriores feitos em acordos diversos, como a criação da Associação Latino-Americana de Livre Comércio - ALALC na década de 1960 que visava uma integração regional baseado na economia, a Associação Latino-Americana de Integração - ALADI em 1980, que substituiu a ALALC, e o Mercado Comum Sul - MERCOSUL.

Sabe-se que uma verdadeira integração física do continente e dos povos da América do Sul deveria objetivar o seu desenvolvimento, e não a expansão dos negócios das grandes corporações mundiais. Esta visão de outra integração possível tem como premissas a democracia e o direito à informação e à autodeterminação dos povos e está balizada na busca pela utilização eficiente dos recursos naturais, de forma apropriada às particularidades regionais, destinada ao crescimento dos mercados e ao desenvolvimento das populações locais, com respeito às suas culturas e ao ambiente onde vivem (PAIM, 2003).

Neste trabalho foi destacado o papel da IIRSA para a exportação de soja para a China, poderíamos também discutir sobre a melhor fluidez da exportação de minérios através da IIRSA. Mas é de fundamental importância, numa pesquisa futura, o estudo da produção da região do MATOPIBA (região de congruência dos estados do Maranhão, Tocantins, Piauí e Bahia, que vem se consolidando como nova fronteira 
agrícola do Brasil) que possivelmente será muito explorada, haja vista as investidas e acordos internacionais com o Japão, e a relação com a IIRSA, e seus efeitos espaciais, como os conflitos no campo identificados pela CPT.

\section{REFERÊNCIAS}

Amigos da Terra; Rios Vivos. IIRSA - Integración en Riesgo - Iniciativa de los gobiernos y las Instituciones Financieras Internacionales para la Integración de la Infraestructura Regional de Sudamérica (IIRSA). Núcleo Amigos da Terra: Brasil/ Rios Vivos: Argentina. 2004.

ANEC - Associação Nacional de Exportadores de Cereais. Exportação de Soja. Disponível em: <http://www.anec.com.br/pt-br/servicos/estatisticas>. Acesso em junho, 2016.

BARTESAGHI, L.; CERONI, M.; DÍAZ, I.; FACCIO, C.. Integración de Infraestructura Regional Sudamericana: otro paso en la explotación de los pueblos y territorios sudamericanos. Amigos de La Tierra: Uruguay, 2006.

COELho, C. N. O aproveitamento econômico dos Cerrados. Revista de Política Agrícola, Brasília, n. 1, p. 1-5, jan./mar., 2001.

COSIPLAN - Conselho Sul-Americano de Infraestrutura e Planejamento. Informações Geográficas. 2017. Disponível em: <http://www.sig.cosiplan.unasursg.org/node15>. Acesso em: outubro de 2017.

CPT - Comissão Pastoral da Terra. Conflitos no Campo - Brasil - 2005. Goiânia: CPT Nacional, 2006.

CPT - Comissão Pastoral da Terra. Conflitos no Campo - Brasil - 2010. Goiânia: CPT Nacional, 2011.

CPT - Comissão Pastoral da Terra. Conflitos no Campo - Brasil - 2015. Goiânia: CPT Nacional, 2016.

IBGE - Instituto Brasileiro de Geografia e Estatística. Produção Agrícola Municipal. Rio de Janeiro: IBGE, 2016.

FUNAI - Fundação Nacional do Índio. Terras Indígenas - 2012. Disponível em: <http://www.funai.gov.br>. Acesso em: outubro de 2017.

INCRA - Instituto Nacional de Colonização e Reforma Agrária. Território Quilombola - 2013. Disponível em: <http://www.incra.gov.br/quilombola>. Acesso em: outubro de 2017.

MARTINS, C. E. Globalização, dependência e neoliberalismo na América Latina. São Paulo: Boitempo, 2011.

MMA - Ministério do Meio Ambiente. Dados Georreferenciados das Unidades de Conservação - 2004. Disponível em: <http://www.mma.gov.br/areas-protegidas/ cadastro-nacional-de-ucs/dados-georreferenciados>. Acesso em: outubro de 2017.

OLIVEIRA, D. J. G. de; GONÇALVES, C. A.; RAMOS FILHO, E. da S. Problematizando a Integração Regional: As conexões entre a Iniciativa para a Integração da Infraestrutura Regional Sul-Americana (IIRSA) e o Programa de Aceleração do Crescimento (PAC)

- Brasil. Revista IDeAS, Rio de Janeiro, v. 7, n. especial, p. 260-304, 2013. 
PAIM, E. S.. IIRSA: É Esta a Integração que queremos?. Núcleo Amigos da Terra: Porto Alegre, 2003.

PORTO-GONÇALVES, C. V.; QUENTAL, P. de A.. Colonialidade do poder e os desafios da integração regional na América Latina. Polis - Revista Latinoamericana, Santiago-Chile, n. 31, 2012.

SANTOS, M.. Economia Espacial: Críticas e alternativas. São Paulo: Hucitec, 1979.

THE ECONOMIST. The Chinese chequebook. Maio, 2015. Disponível em: <http:// www.economist.com/news/americas/21651889-latin-america-needs-be-more-hardheaded-its-big-new-partner-chinese-chequebook>. Acesso em Junho, 2016.

VERDUM, R.. Obras de infra-estrutura no contexto da integração Sul-Americana. IN: VERDUM, R. (Org.) Integração, usinas hidroelétricas e impactos socioambientais. Brasília: INESC, p. 13-40, 2007.

ZIBECHI, R.. IIRSA: la integración a la medida de los mercados. Programa de las Américas, Silver City-EUA, p. 1-6, 2006.

Recebido em setembro de 2016

Revisado em novembro de 2017

Aceito em fevereiro de 2018 
